\title{
A sensibilidade intermidial na constituição dos sujeitos em "Coisas que acarinho e me morrem entre os dedos", de Dulce Maria Cardoso
}

\author{
Larissa Fonseca e Silva ${ }^{\mathrm{i}}$ \\ Miriam de Paiva Vieira ${ }^{\text {ii }}$
}

\section{RESUMO}

Em "Coisas que acarinho e me morrem entre os dedos", conto da autora portuguesa Dulce Maria Cardoso, fragmentos que fazem referências a serviços da ferramenta de busca Google e espaços pessoais na internet, tais como blog e Facebook, geram pausas que desautomatizam (MARTONI, 2020) o que seria uma leitura convencional, efeito esse potencializado ao serem escritos em uma fonte diferente daquela que é padrão no texto. Ao mesmo tempo, quando esses fragmentos são inseridos em meio ao parágrafo de narração da protagonista, passam a ser também a voz dela, em um movimento cuja descrição partirá aqui das noções de gesto escritural (DOMINGOS; JUNGBLUT, 2020) e sensibilidade intermidial (MARTONI, 2020). Assim sendo, o objetivo deste artigo é demonstrar como a narradora-personagem constrói a si mesma e ao seu Outro a partir da evocação a fragmentos extraídos das novas mídias.

Palavras-chave: Dulce Maria Cardoso; Intermidialidade; Desautomatização da leitura; Sensibilidade intermidial; Gesto escritural.

\begin{abstract}
In "Coisas que acarinho e me morrem entre os dedos", a short story by the Portuguese author Dulce Maria Cardoso, fragments of Google search engine tools and private spaces on the internet, such as blog and Facebook, generate pauses that deautomatize (MARTONI, 2020) what would be a conventional reading. This effect has its potential enhanced by the use of different fonts from the chosen print standard. At the same time, when these fragments are inserted within a paragraph narrated by the protagonist, they also become her voice, in a movement wherein started from the concept of scriptural gesture (DOMINGOS; JUNGBLUT, 2020) and of intermedial sensitivity (MARTONI,
\end{abstract}

\footnotetext{
${ }^{\text {i }}$ Mestranda em Teoria Literária e Crítica da Cultura, Linha de Pesquisa LMC (Literatura e Memória Cultural) no PROMEL (Programa de Mestrado em Letras da UFSJ), desenvolve o projeto de dissertação intitulado Os ponteiros que nos situam: memória, tédio e identidade no romance Campo de Sangue, de Dulce Maria Cardoso. ORCID: https://orcid.org/0000-0003-4501-9293 | larissafonsil@yahoo.com.br
}

\footnotetext{
ii Professora Adjunta da Universidade Federal de São João del-Rei. ORCID: https://orcid.org/0000-0001-9851-0217 | miriamvieira@ufsj.edu.br
} 
2020). Thus, the aim of this article is to demonstrate how the narrator-character builds herself and her Other by evoking new media fragments.

Keywords: Dulce Maria Cardoso; Intermediality; Reading deautomatization; Intermedial sensitivity; Scriptural gesture.

\title{
INTRODUÇÃO
}

"Nós podemos ver palavras e ouvir imagens" (MITCHELL, 1996, p. 56)ํ. Essa afirmação é retirada do ensaio "Palavra e imagem", no qual W. J. T. Mitchell discute e demonstra a fragilidade das fronteiras entre essas duas mídias básicas (ELLESTRÖM, 2017, p. 89). Como exemplo, pede que notemos o contraste que fazem as letras sobre um fundo branco, isto é, pede que nos detenhamos na forma da palavra, em sua aparência visual, para além do que ela simboliza. Assim, percebemos o potencial de transformação da palavra em imagem:

Em suma, elas [as palavras] apresentam uma face dupla tanto para os olhos quanto para os ouvidos: de um lado é o signo articulado da linguagem; de outro é uma gestalt formal, visual ou auditiva, uma imagem ótica ou acústica. Geralmente olhamos apenas para uma face e ignoramos a outra: não prestamos muita atenção na tipografia ou no aspecto gráfico de um texto; não ouvimos os sons das palavras, preferindo nos concentrar no sentido que elas carregam. Mas é sempre possível mudar nossa atenção, deixar

\section{aquelas marcas pretas sobre um fundo branco}

\begin{abstract}
se tornarem objetos de atenção visual ou sonora, como nesse exemplo autorreferencial. Nós somos encorajados a tal mudança através de usos poéticos e retóricos da linguagem que trazem à tona a sonoridade das palavras, ou através de usos ornamentais e artísticos da escrita (como nas iluminuras, na caligrafia) que trazem à tona a aparência visual das letras. Mas o potencial da mudança “da palavra para a imagem" está sempre ali, mesmo que nas formas mais simples e desadornadas da escrita e da fala (MITCHELL, 1996, p. 51, grifo do autor) $)^{2}$.
\end{abstract}

Quando lemos um texto, tendemos a nos tornar inconscientes das letras enquanto imagens físicas, impressas no papel. As imagens que nos importam são outras: aquelas que podem ser criadas em nossa mente à medida em que corremos os olhos sobre a página. 
As palavras, naturais a nós desde nossa alfabetização e cumprindo, então, sua função simbólica, nos passam despercebidas. O processo de leitura já nos é rápido e automático.

Se em um texto, porém, o autor decide inserir fontes tipográficas diferentes daquela escolhida como padrão, ele desautomatiza a percepção da leitura (MARTONI, 2020, p. 96). Essa desautomatização, conforme colocado por Alex Martoni em "O que vemos quando lemos? Tipografia como categoria de análise literária", faz com que o leitor não apenas note uma mudança na forma da palavra, mas atribua um efeito de sentido a essa mudança. No mesmo artigo, Martoni aponta que as possibilidades tipográficas como estratégia literária começam a virar tendência com o advento das máquinas:

Esses gestos de exploração dos potenciais expressivo e sugestivo da visualidade das formas tipográficas apresentam, como condição de possibilidade, a formação de uma nova sensibilidade do escritor em face às transformações tecnológicas operadas pela modernidade (MARTONI, 2020, p. $85)$.

E completa:

\begin{abstract}
Parece-nos legítimo [...] apontar a formação de uma espécie de sensibilidade intermidial como uma das condições de possibilidade para a emergência das experiências tipográficas no plano literário. Nesse sentido, o imaginário e os modos de expressão do escritor estão em diuturna interação com o conjunto de novas experiências perceptivas, cognitivas e sensoriais produzidas nas suas relações com os objetos sociotécnicos. Recordemo-nos a lição de Benjamin: "No decorrer de longos períodos históricos, modifica-se não só o modo de existência das coletividades humanas, mas também a sua forma de percepção" (BENJAMIN, 2012, p. 13). Não há, portanto, uma percepção pura, selvagem; indiferente aos modos técnicos de produção (MARTONI, 2020, p. 86, grifo do autor).
\end{abstract}

Ao conceito de sensibilidade intermidial, podemos unir outro termo: gesto escritural, conceituado por Ana Cláudia Munari Domingos e Helena Jungblut (2020) em

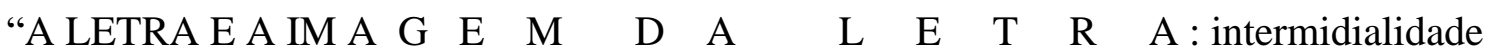
em Vista parcial da noite, de Luiz Ruffato". Nesse artigo, as autoras, apoiadas na proposta de Lars Elleström para o estudo de relações entre mídias diferentes, apontam a mudança tipográfica em um texto literário enquanto um fenômeno intermidial, visando aquilo o que acontece em uma relação entre a imagem verbal e não-verbal da palavra.

Elleström propõe o entendimento da noção de mídia a partir de três aspectos teóricos que se complementam: mídias qualificadas, mídias básicas e técnicas. Nas mídias qualificadas, diferentes modalidades - que Elleström entende como fundamentos 
essenciais em qualquer mídia, sendo elas modalidade material, sensorial, espaçotemporal e semiótica - se combinam, em seus diferentes modos, para formar a materialidade, a percepção e a cognição necessárias para que "depreendamos" as mídias dentro de seus contextos históricos e socioculturais (2017, p. 49-100).

Domingos e Jungblut (2020) escolhem, para a definição de gesto escritural, dar ênfase à modalidade semiótica da configuração midiática que, no caso do objeto que elas analisam, é um romance. Lars Elleström (2017) aponta que

\begin{abstract}
A modalidade semiótica [...] envolve a criação de significado na mídia concebida de forma espaçotemporal por meio de diferentes tipos de raciocínio e de interpretações de signos. A criação de significado já se inicia na apreensão e na organização inconsciente dos dados sensoriais percebidos pelos receptores e continua no ato consciente de encontrar conexões relevantes dentro da estrutura espaçotemporal da mídia e entre a mídia e o mundo ao seu redor (ELLESTRÖM, 2017, p. 70).
\end{abstract}

De maneira que Domingos e Jungblut lembram que "Um romance que brinca com as cores da tipografia afeta nossa modalidade sensorial, pois esperamos interagir com as palavras em sua modalidade tipográfica comum ao códice impresso de um romance adulto - preto no branco da página" (DOMINGOS \& JUNGBLUT, 2020, p. 136). Elas explicam como:

[...] É na modalidade semiótica que a comunicação dos produtos de mídia constrói semiose pela representação de objetos, que [...] pode ser simbólica, icônica ou indicial. Nos romances, a representação sígnica é sobretudo simbólica, visto que as palavras representam por convenção. [...] Se o uso da cor para evocar sentido acontece em um tipo de mídia cujos modos essenciais não incluam a cor, então podemos, sim, pensar que está acontecendo aí uma invasão de uma mídia pela outra. Ou seja, temos aí um fenômeno intermidial: o romance está usando um modo que não é o seu, mas que é, por exemplo, da pintura, para produzir significado. A multimodalidade, levando em conta o conceito de Elleström de modalidade, refere-se à combinação de diferentes modos [...]. Os romances cujas palavras também constroem representações icônicas como as da pintura são, assim, multimodais. Esses modos também podem se distinguir em submodos, por exemplo, um romance cujas palavras se apresentam em diferentes fontes também pode ser considerado multimodal (DOMINGOS \& JUNGBLUT, 2020, p. 137).

Essa multimodalidade é, também, um gesto escritural do autor (DOMINGOS; JUNGBLUT, 2020). Nas palavras das autoras:

Quando contrapomos a distinção das vozes narrativas pelo uso de diferentes tipografias à instância do narrador, percebemos que ele atua através de uma 
marca que não tem relação com a narração romanesca de contar a história através das palavras, pois o narrador é uma figura inventada, ele não "monta" o texto, mas surge através dele. É nesse sentido que podemos dizer que o narrador é também um escritor, ao dimensionar a escritura do texto ao narrar através desse gesto que é, assim, escritural (DOMINGOS \& JUNGBLUT, 2020, p. 148).

"Coisas que acarinho e me morrem entre os dedos", conto da autora portuguesa Dulce Maria Cardoso, permite uma exemplificação dos conceitos de desautomatização da leitura, sensibilidade intermidial e gesto escritural. Ao mesmo tempo, por meio desses conceitos, podemos ampliar suas camadas de significação e enriquecer, assim, a sua leitura, tal como será demonstrado a seguir.

\section{SUJEITOS INTERMIDIALMENTE CONSTRUÍDOS}

"Coisas que acarinho e me morrem entre os dedos" foi inserido na coletânea Tudo são histórias de amor, publicada pela Tinta-da-china Brasil em 2017. Originalmente, porém, o texto foi escrito para a Coleção Contos Digitais da Biblioteca Digital DN em 2012, suplemento oferecido pelo portal de notícias português Diário de Notícias. Por meio da entrevista concedida ao portal no mesmo ano, passamos a saber que o suporte digital em que o conto circularia influenciou não apenas sua temática, mas também a forma em que ele foi escrito. Quando perguntada sobre o motivo da escolha dele para o suplemento, a autora responde:

\footnotetext{
Escolhi porque é um conto muito moderno. E que tem que ver com isto, com a internet, com o facto ${ }^{3}$ de conhecermos os outros através da internet, com encontrar com todo esse mundo de informação que por aí anda. E que também é um mundo de pessoas, não é? Tendemos a esquecer isso. E justamente porque é um suporte digital, porque sei que fazia algum sentido acompanhar a linguagem com o suporte onde estava a apresentar o conto, aliás, meus contos em geral são mais clássicos, até têm uma linguagem mais rural, e mais antiga, mais arcaica, e neste quis me... Tem muito inglês, por exemplo. Tem muitas, muitas partes em inglês, porque também é uma língua que... É a língua franca da internet, não é? [...] (DULCE, 2012, s.p.).
}

No enredo de "Coisas que acarinho e me morrem entre os dedos", temos uma narradora-personagem prestes a se encontrar com um homem que, a propósito de seu trabalho, a procurou no Facebook. Esse trabalho não é explicitado ao leitor, que pode, inadvertida ou propositalmente, pensar na escritora Dulce Cardoso, confundindo-a com a 
narradora-personagem. A confusão nem é de todo leviana, visto que tanto os gestos escriturais que se apresentam no texto quanto uma passagem com índices autobiográficos, ambos a serem apontados adiante, também permitem uma leitura do conto por um viés autoficcional.

Quanto ao encontro, é a própria narradora-personagem que o propõe, e ele gera uma expectativa que parece fruto de um interesse romântico pelo homem cuja foto de perfil no Facebook é descrita como a de uma pessoa atraente. A narradora, contudo, define a expectativa dentro de uma curiosidade generalizada pelo Outro. Como explica a autora Dulce Cardoso na entrevista ao Diário de Notícias, o Outro nos é sempre desconhecido, por mais que possamos "googlar" seu nome e tentar descobrir algo por meio do que encontramos nas pesquisas e nas redes sociais.

Na manhã do encontro, após olhar rapidamente as notícias, a narradora explica: "Não me interessa assim tanto o que acontece por esse mundo fora, mas ao acordar ainda me interessa menos o que acontece na minha vida. E as notícias que não nos dizem respeito de forma directa distraem-nos" (CARDOSO, 2017, p. 138). A distração que ela menciona também é provocada no leitor enquanto desautomatização da leitura quando, logo a seguir, é inserido no texto um trecho de uma notícia sobre Bangladesh, em fonte diferente da utilizada como padrão ${ }^{4}$ e mais similar àquela da ferramenta de busca Google:

Figura 1: Notícia sobre Bangladesh inserida no conto.

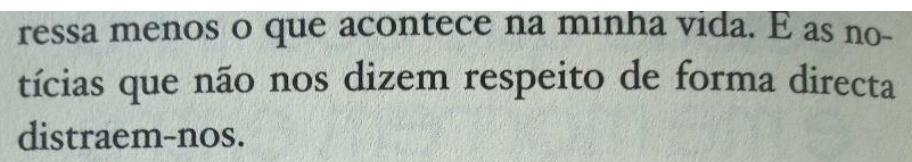

Um avião de pequeno porte, o Nanchang PT-6, prefixo 3806, da Força Aérea de Bangladesh (Bangladesh Air Force

- BAF) teve de fazer uma aterragem de emergência durante uma tempestade na noite desta quarta-feira (25) em Raigram, no distrito indiano de Murshidabad, a 80 quilómetros da fronteira entre os dois países. 0 piloto, que vinha de Jassor, sofreu ferimentos ligeiros.

Do Bangladesh, pouco mais sabia do que o nome. Não é difícil familiarizarmo-nos com o nome das

Fonte: CARDOSO, 2017, p. 138. 
O excerto sobre Bangladesh, porém, não é mera exemplificação de notícia: percebendo que pouco sabia sobre o país, a narradora-personagem o procura no Google, correndo os olhos sobre os resultados que aparecem e que também são transpostos ao conto em fonte diferenciada. É a partir dessa rápida pesquisa que uma pergunta, aparentemente sem relação com os resultados expostos, fica em seu subconsciente, em inglês: "When is Bangladesh going to disappear?" (CARDOSO, 2017, p. 139, grifo da autora).

Essa pergunta teria surgido à cabeça da narradora no momento do encontro, mas também não veio sem propósito: adiante na leitura, percebemos a associação do questionamento ao medo da própria personagem de que as coisas desapareçam. De que as coisas morram entre os dedos após acarinhadas, se formos aludir ao título que, aliás, é o verso de um poema que a narradora-personagem encontra quando tentava descobrir algo sobre o homem do Facebook. Esse poema estava em um blog chamado Machina ex Deus, cujo dono poderia ser o homem e cujos poemas ali arquivados, talvez, se referissem a ela.

Com isso, a narradora vai construindo seu Outro, que no conto é o homem do Facebook, a partir das postagens do blog e da possibilidade de que seu autor, homônimo ao homem do Facebook, seja o próprio. É uma escolha consciente que ela faz:

\begin{abstract}
Mente-se tão bem na internet como na vida, e aquilo [os posts no blog] podia ser tudo inventado. Podia ser só uma questão de estilo. Mas quis acreditar que não e li como se fosse verdade. Era verdade tudo o que tinha lido. O homem do Facebook, o Machina ex Deus e aquele com quem iria encontrar-me dali a pouco eram todos o mesmo homem. Mesmo assim, não sabia quase nada sobre ele. Das mensagens que tínhamos trocado, para além de saber que gostava do meu trabalho, sabia o nome, a profissão e pouco mais. Ah, e havia as fotografias. Que podiam ser falsas (CARDOSO, 2017, p. 144).
\end{abstract}

Imaginando que é com o autor de Machina ex Deus que, afinal, vai se encontrar, passa a se imaginar como a mulher descrita em seus poemas: "Eu podia ser quase todas as mulheres de que ele falava porque elas faziam coisas que eu costumo fazer" (CARDOSO, 2017, p. 144). Assim é que constrói a ambos, o Eu e o Outro, a partir dos resultados de pesquisas no Google que se entrelaçam ao conto - em trechos escritos com fontes diferenciadas que, por sua vez, tornam o texto dinâmico, polifônico e intermidiático. A partir da tipografia diferenciadora, é como se pudéssemos ouvir "a voz do Google”, pertencente às mídias digitais, no texto publicado no livro físico, mídia 
tradicional. Ao mesmo tempo, os trechos em fonte diferente podem ser entendidos como gesto escritural, isto é: podemos sentir, no texto, a presença não apenas da narradora, mas da escritora, Dulce Maria Cardoso, que escreve e edita o texto.

A presença da autora também se faz por meio de um parágrafo em especial:

\begin{abstract}
A ameaça do provisório sempre me assustou. Já perdi tanta coisa. Perdi um continente e a cidade em que cresci, perdi o meu pai, perdi uma caneta de tinta permanente e um guarda-chuva com um arco-íris, perdi a minha cadela Fly e a coleira com sininho que ela usava. Perdi tempo. (CARDOSO, 2017, p. 149).
\end{abstract}

Aqui, podemos (escolher) ler um importante índice autobiográfico da escritora: o fato de ter precisado deixar, aos onze anos, e por ocasião de uma guerra civil, o continente em que cresceu.

Dulce Cardoso mudou-se com os pais e a irmã para Angola nos anos sessenta, dentro do contexto do incentivo da ditadura salazarista à maior presença de portugueses no que, então, se convencionava chamar "províncias ultramarinas". Com a Revolução dos Cravos em 1974 e a independência das colônias conquistada nas Guerras de Libertação, os portugueses e filhos de portugueses em África precisaram se retirar às pressas, a fim de evitar a retaliação por parte dos revolucionários. Assim, em novembro de 1975, Dulce Maria Cardoso volta para Portugal como "retornada", que era a denominação dada àqueles que vinham das ex-colônias. Desse modo, é possível ler "Perdi um continente e a cidade em que cresci" como um índice autobiográfico dentro de um texto literário. "Os fatos autobiográficos fabulam [...]" (SANTIAGO, 2008, p. 176), já dizia Silviano Santiago em "Meditação sobre o ofício de criar".

Um pouco mais de curiosidade por parte do leitor poderia levá-lo a se perguntar, por exemplo, se Dulce Cardoso teria tido uma cadela chamada Fly. O que importa à leitura aqui proposta, porém, é que a possível inserção autobiográfica vem após um trecho (em fonte diferenciada) de nova pesquisa sobre Bangladesh e que retoma, justamente, a pergunta sobre quando Bangladesh desapareceria. A narradora descobre que, devido a uma localização geográfica desfavorável, sujeita a inundações, o país poderia se extinguir nos próximos vinte anos.

Bangladesh, então, pode ser associado à Angola colonial, que não mais existe. Isso, é claro, se aceitarmos que os índices autobiográficos que sucedem o trecho da 
pesquisa possam fazer do conto uma narração autoficcional, pensando na definição que Anna Faedrich dá ao termo "autoficção" no ensaio "Autoficção: um percurso teórico":

[...] prática literária contemporânea de ficcionalização de si, em que o autor estabelece um pacto $^{5}$ ambíguo com o leitor, ao eliminar a linha divisória entre fato/ficção, verdade/mentira, real/imaginário, vida/obra, etc; o tempo presente da narrativa e o modo composicional da autoficção, que é caracterizado pela fragmentação, uma vez que o autor não pretende dar conta da história linear e total de sua vida; o movimento da autoficção, que é da obra de arte para a vida - e não da vida para a obra, como na autobiografia -, potencializando o texto enquanto linguagem criadora; identidade onomástica entre autor, narrador $e$ protagonista, que pode ser explícita ou implícita, desde que exista o jogo da contradição, criado intencionalmente pelo autor no próprio livro. E, por fim, a palavra-chave que marca a autoficção como um gênero híbrido: a indecidibilidade (FAEDRICH, 2016, p. 44-45, grifos da autora).

Ao mesmo tempo em que Bangladesh pode, pela escolha da leitura autoficcional, se referir à extinta Angola colônia, pode, também, se relacionar ao próprio homem do Facebook, que poderia sumir após alguns encontros. A pergunta "When is Bangladesh going to disappear?" (CARDOSO, 2017, p. 139, grifo da autora) fica na cabeça da narradora-personagem no primeiro encontro com o homem. Desse modo, entendemos que, em suma, Bangladesh está ligado aos apegos a tudo o que não dura para sempre - às coisas que acarinhamos e nos morrem entre os dedos. Ou, como a narradora diz: "Não quero amar o que não pode, para sempre, aceitar-me de regresso" (CARDOSO, 2017, p. 149).

A narradora chegou mesmo a pesquisar sobre voos para Bangladesh, em um parágrafo em que, novamente, e como várias vezes ao longo da narrativa, se mistura à fonte padrão a fonte diferenciada - movimento que, como já demonstrado, também é um fenômeno intermidiático e polifônico:

Figura 2: Pesquisa sobre voo para Bangladesh inserida no conto.

Momondo. Pesquisei um voo. De: Lisbon (LIS), Portugal. Para: Barisal (BZL), Bangladesh. Só ida. Data da partida: 27-04-2012. Se houvesse um voo ao fim do dia, mesmo indo ao encontro, daria tempo de fazer a mala. A pesquisa demorou uns instantes. Ø resultados. Não foi possível encontrar quaisquer voos que correspondam ao seu pedido. Por favor, tente novamente, talvez com datas ou aeroportos alternativos. Um bom conselho. Assim faria. Mais tarde.

Fonte: CARDOSO, 2017, p. 146. 
Ao final do conto, após a conclusão sobre não amar o que não a aceita de regresso, aparece o seguinte trecho:

Figuras 3 e 4: Apelo da narradora no conto inserido no livro.
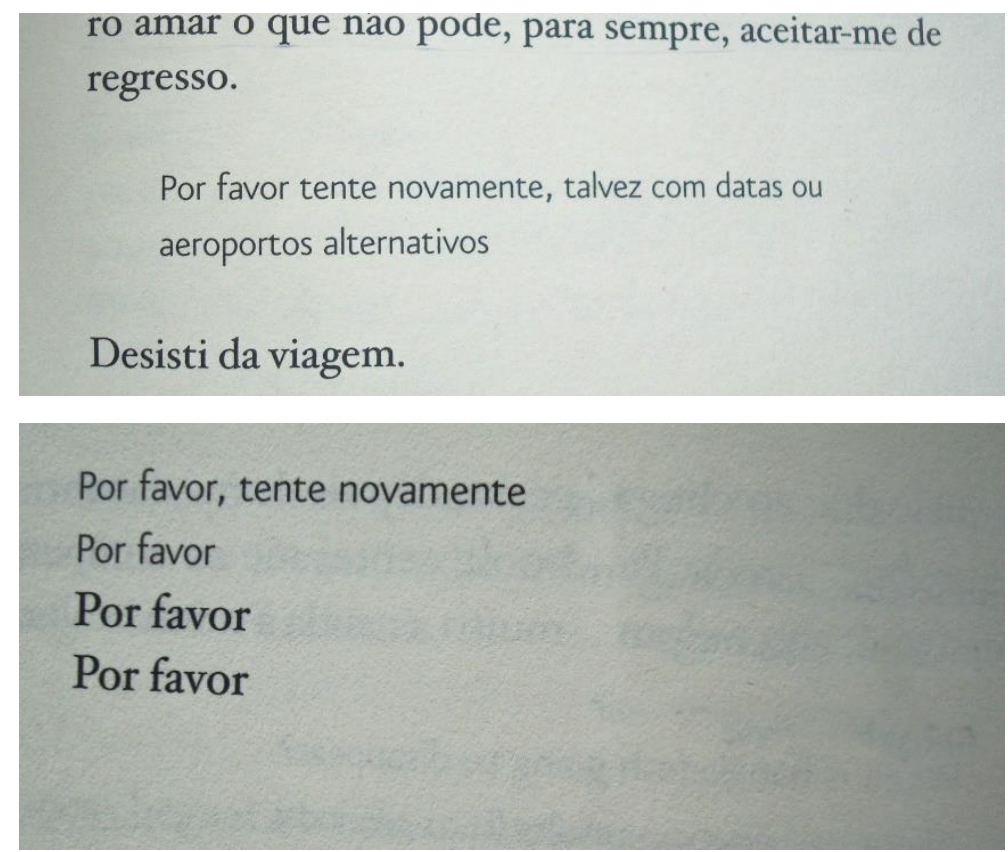

Fonte: CARDOSO, 2017, p. 149-150.

Aos quatro apelos que aparecem, dois se associam à pesquisa e dois, pelo retorno à fonte padrão, são a voz da própria narradora. No conto publicado na Coleção Contos Digitais da Biblioteca Digital DN, a mudança de fonte entre os quatro apelos não ocorria, e aqui se percebe como o efeito de sentido construído é outro, bem menos íntimo e enfático, demonstrando, então, a relevância da tipografia na constituição semântica:

Figura 5: Apelo da narradora no conto do suplemento digital.

Não sei ir ao Bangladesh. Não quero amar o que não possa aceitar-me de regresso.
Por favor tente novamente, talvez com datas ou aeroportos alternativos
Desisti da viagem.
Por favor, tente novamente
Por favor
Por favor
Por favor

Fonte: CARDOSO, 2012, p. 13. 
Assim é que "Coisas que acarinho e me morrem entre os dedos", feito especialmente para uma mídia digital e transposto para a mídia tradicional livro, aprimora conservando daquela, e da própria época em que é escrito, a sensibilidade intermidial. Em outras palavras, usa a mudança de fontes tipográficas para marcar uma voz que é diferente da voz da narradora e que faz referência às mídias digitais. Além disso, essa mudança de fontes é gesto escritural da autora Dulce Maria Cardoso, e temos, pela desautomatização que se provoca na leitura, a percepção dos novos sentidos que se constroem no conto ao mesmo tempo em que são construídos os sujeitos da narrativa. Ao mesmo tempo, também, em que nos (re)construímos como leitores: para além de nos concentrarmos no enredo, distraímo-nos, junto à narradora, em suas pesquisas e procrastinações no Google antes de um primeiro encontro.

\section{CONSIDERAÇÃO FINAIS}

Neste artigo, demonstrou-se como "Coisas que acarinho e me morrem entre os dedos", da autora portuguesa Dulce Maria Cardoso, torna-se um fenômeno intermidial quando faz uso de fontes diferenciadas daquelas que são padrão no corpo do texto, levando-o para além de sua função simbólica. Desse modo, se as palavras, por um lado, se tornam imagens (MITCHELL, 1996), por outro elas desautomatizam (MARTONI, 2020) nossa leitura: “[...] nosso olhar é tomado por uma espécie de vertigem que borra os contornos da superfície do significante para que possamos mergulhar na profundidade do significado do texto" (MARTONI, 2020, p. 89). Esse movimento dinamiza o texto e o torna polifônico, especialmente quando a mudança tipográfica ocorre dentro de um mesmo parágrafo, como se demonstrou em alguns exemplos.

Ademais, as fontes diferenciadas permitem tanto que as associemos às mídias digitais, dado o formato escolhido e o contexto do enredo do conto, quanto que vejamos, nelas, e por trás da narradora-personagem, a presença da autora montando o texto, em um exemplo de gesto escritural. 'É através dessa 'escritura' que se inscreve por traços, por rastros que deixa atrás de si, que são oferecidas pistas de processos de subjetivação [do autor]” (DOMINGOS \& JUNGBLUT, 2020, p. 155). Essas escolhas, além de tornar "Coisas que acarinho e me morrem entre os dedos" propício ao meio em que foi publicado originalmente, isto é, o suplemento digital do Diário de Notícia, acrescentam camadas de 
sentido ao conto e à construção dos personagens. Com isso, o "Eu" (narradorapersonagem) pode ser também a mulher dos poemas e Dulce Maria Cardoso (pelo gesto escritural e pela leitura autoficcional), e o "Outro", que é o homem do Facebook, pode ser, igualmente, o autor do blog Machina ex Deus.

A estratégia das fontes diferenciadas também presentifica o texto dentro da sensibilidade intermidial (MARTONI, 2020) que é familiar ao leitor contemporâneo, gerando identificação tanto com o que se narra quanto com a forma como se é narrado.

\section{Referências}

CARDOSO, Dulce Maria. Coisas que acarinho e me morrem entre os dedos. In: Tudo são histórias de amor. Rio de Janeiro: Tinta-da-china Brasil, 2017.

CARDOSO, Dulce Maria. Coisas que acarinho e me morrem entre os dedos. Contos Digitais DN, 2012. Disponível em: https://app.box.com/s/gljemjc7jz5fxcd2m9i9nntz2xvtij59. Acesso em: 11 abr. 2021.

DOMINGOS, Ana Cláudia Munari; JUNGBLUT, Helena. A LETRA E A IM A G E $M \quad D \quad A \quad L \quad E \quad T \quad R \quad A$ : intermidialidade em Vista parcial da noite, de Luiz Ruffato. Revista do Programa de Pós-graduação em Artes Visuais da UnB, Brasília, v. 19, n. 1, p. 130-157, 2020.

DULCE Maria Cardoso fala dos encontros do dia-a-dia. Diário de notícias. 2012. Disponível em: https://www.dn.pt/artes/dulce-maria-cardoso-fala-dos-encontros-do-diaa-dia-2899545.html. Acesso em: 30 mar. 2021.

ELLESTRÖM, Lars. As modalidades das mídias: um modelo para a compreensão das relações intermidiáticas. Midialidade: ensaios sobre comunicação, semiótica e intermidialidade. Porto Alegre: EdiPUCRS, 2017, p. 54-60.

FAEDRICH, Anna. Autoficção: um percurso teórico. Criação \& Crítica, n. 17, p. 30-46, 2016.

LEJEUNE, Philippe. O pacto autobiográfico. In: LEJEUNE, Philippe. $O$ pacto autobiográfico; de Rousseau à Internet. Belo Horizonte: Ed. UFMG, 2008, p. 13-47.

Autoficções \& Cia. In: NORONHA, Jovita Maria Gerheim (Org.). Ensaios sobre a autoficção. Tradução de Jovita Maria Gerheim Noronha e Maria Inês Coimbra Guedes. Belo Horizonte: Editora UFMG, 2014, p. 21-37.

MARTONI, Alex. O que vemos quando lemos? Tipografia como categoria de análise literária. In: FIGUEIREDO, Camila A. P de; LIMA, Cecília Nazaré de; ARBEX, Márcia; 
VIEIRA, Miriam de Paiva; et al (Org). Escrita, som, imagem: leituras ampliadas. 1. ed. Belo Horizonte: Fino Traço, 2020, p. 83-100.

MITCHELL, W. J. T. Word and image. In: NELSON, Robert S.; SHIFF, Richard (Ed.). Critical Terms for Art History. 2 ed. Chicago: University of Chicago Press, 1996, p. 51-61.

SANTIAGO, Silviano. Meditação sobre o ofício de criar. Revista Aletria. Belo Horizonte, n.18, 2008, p.173-178.

Recebido em: 27/05/2021

Aceito em: 19/07/2021

\footnotetext{
${ }^{1}$ Tradução inédita de Augustto Cipriani.

${ }^{2}$ Idem.
}

${ }^{3}$ Neste artigo, optamos por manter a ortografia portuguesa original no trecho da entrevista e nos trechos selecionados do conto.

${ }^{4}$ A primeira ocorrência de uma fonte diferenciada no conto é quando, logo ao início, a narradora imagina um SMS encorajador enviado por Deus, em inglês, pela manhã.

${ }^{5}$ Por pacto, a autora faz referência aos postulados do teórico francês Philippe Lejeune sobre a autobiografia em O pacto autobiográfico, publicado em 1975. Esse pacto pressupõe a unidade entre o nome do autor, nome do narrador e nome do personagem como um dos critérios para que um livro seja rotulado como autobiográfico (LEJEUNE, 2008). A partir dessa definição, Lejeune cria uma tabela em que estabelece as diferenças entre autobiografia e romance, mas, não conseguindo definir nem como romance nem como autobiografia uma possível obra em que o teor fosse romanesco e, ainda assim, houvesse correspondência nominal entre autor, narrador e personagem, deixa em branco essa "casa". É Serge Doubrovsky quem primeiro irá preenchê-la, propondo a nomenclatura "autoficção": "Em seu 'romance' Fils, Serge Doubrovsky dará a seu personagem seu próprio nome. Essa ambiguidade do contrato de leitura traduz a ambiguidade de seu projeto: veracidade da informação, liberdade de escrita. [...] Fils é batizado 'autoficção'. A palavra não serve de subtítulo genérico (a indicação será 'romance'), mas é proposta na quarta capa do livro [...]" (LEJEUNE, 2014, p. 23). A partir da publicação de Fils, o termo autoficção passará por uma série de reconceituações por parte de Doubrovsky e outros teóricos, tal como Anna Faedrich (2016) demonstra e resume em seu ensaio. 